\title{
Women in situations of violence: limits of assistance
}

Ethel Bastos da Silva ${ }^{1}$

Stela Maris de Mello Padoin ${ }^{1}$

Lucila Amaral Carneiro Vianna ${ }^{2}$

${ }^{1}$ Centro de Educação Superior Norte do Estado do Rio Grande do Sul, Universidade Federal de Santa Maria. Av. Independência 3751 , Vista Alegre. 98300-000 Palmeira das Missões RS Brasil. ethelbastos@hotmail.com ${ }^{2}$ Escola Paulista de Enfermagem, Universidade Federal de São Paulo.

\begin{abstract}
This paper analyzes the limitations of the care of professionals of family health teams provided to women in situations of violence in the integrated care network in a city in the northwest region of Rio Grande do Sul state, Brazil. The data is part of a survey conducted with six teams participating in family health care in the course of eight meetings, in which the group identified the limits and potential of the practice. The causes of limits, solutions and improvement actions were discussed in a movement of reflection, action and learning. The empirical material was recorded, transcribed and subjected to Bardin's thematic content analysis. The results show the lack of coordination between the sectors of the network; lack of protocol, flow and organization of reference and counter-reference; inefficiency of police, judiciary and security sectors; and the lack of professionals to work on violence against women and in the perspective of the network as restrictive conditions for efficient practice. The need is highlighted for greater support of municipal managers to the professionals for networking and encouragement through the qualification and ongoing education courses that address issues such as gender equity, guarantee of rights and a care network.
\end{abstract}

Key words Violence against women, Health professional, Family health program, Social network 


\section{Introduction}

Violence against women has been the theme of much discussion due to its frequency. In the world, $35 \%$ of women suffer from physical or sexual violence perpetrated by either their partner or another party, depending on region, culture, education and existence of more or less traditional social norms placing male authority over women, which is also recognized as gender violence. This issue requires direct interventions focused on equality of rights and protection and safety. As such, the World Health Organization (WHO) recommends that health care be offered in several different locations/points and professionals be prepared to provide intersectoral responses $^{1}$.

Some international studies point to the adoption of holistic and intersectoral service models, and suggest that Primary Care (PC) managers must find forms in which to integrate police, security, legal and social worker services to ensure that women in situations of violence might benefit from this type of approach ${ }^{2,3}$.

In Brazil, the services most sought out by women in situations of violence are police/police station and emergency room, in the case of injuries requiring medical care. Most women access the integrated network through these two institutions and the practice is limited to criminal and medical responses ${ }^{4,5}$. This supply-demand proposal is determined by assistance and practice in both supply and demand. Reducing violence to a crime or mental illness makes other aspects of the problem - social, cultural and political unfeasible. As such, proposing a transversal intervention means creating a new model for the organization of services that considers demands for needs as the conceptual basis for practices with responses that seek to promote quality of life and access to rights ${ }^{6}$.

The care network model is the most recommended according to many academics in the area of violence against women ${ }^{6-9}$. The network may be accessed from any location and patients must transit through the services that make up the network. Services are horizontally related, in which each has its own duties, all of which are essential and carry the same weight ${ }^{7}$.

The national violence against women pact recommends a number of actions based on the assumption that gender violence is transversal and that responses must be intersectoral and extensive. The horizontal character of this response is structured based on partnerships between sec- tor agencies and representatives of each sphere of government (Ministries, Departments, Regional Offices), while vertically, this structure brings together both national and local policies in the health, justice, education, labor and public security areas, among others. The extensive nature of this response allows for the execution of policies at a local level. And, based on these assumptions, the official document acts as a commitment that actions be based on this care model and spread to the different states and cities of Brazil ${ }^{8}$.

One healthcare service that makes up the network within Primary Care (PC) is the Family Health Strategy (ESF, acronym in Portuguese), considered as the entrance to the healthcare network. In this sense, women in a situation of violence may be aided under the ESF by teams and then sent for specialized healthcare services and those from other complementary sectors, given the complexity and transversal character of the problem?.

The creation of a healthcare network for women in situations of violence has been a challenge for managers and professionals in the Primary Care, all of whom recognize the magnitude of the issues and the need to address this situa$\operatorname{tion}^{10}$. As such, the efficiency of actions depends on intersectoral work and strong, transparent public policies, in addition to adequately trained professionals.

The studies that have analyzed services offered by healthcare networks point out issues such as a lack of articulation between services, shared services, communication and interaction between professionals ${ }^{5,6}$. Services offered by the network must be advertised to a greater extent to ensure that women seek out support ${ }^{5}$.

Understanding the limits that professionals that make up ESP teams face during their work within the healthcare network in the context of the study may contribute to a reflection and the creation of strategies that improve on care to women in situations of violence at the unit and in concert with other complementary sectors.

Thus, this study seeks to analyze the limits on practices to aid women in situations of violence provided by family health teams within the healthcare network.

\section{Method}

This study opted to employ the Participatory Research (PR) method, which is a type of social study in which the community being studied 
participates in the analysis of its own living conditions in an effort to generate change that will benefit all of those involved in the process. This method is considered an educational research operation focused on action. The PR method works to integrate academic and practical knowledge of the world held by intellectuals and laborers and, as a result, leads to the observation of transformations that may be either reformist or conservative $^{11}$.

This PR method followed the four phases organized by Le Boterf ${ }^{12}$. The first phase: institutional preparation and research methodology; second: preliminary and provisory study of the zone and population to be studied; third: critical analysis of problems considered as priorities and those that researchers hope to study; and fourth: programming and execution of an action plan.

Participants were professionals that worked on Family Health Teams, representing the following categories: nurse, doctor, nurse technician, licensed practical nurse (LPN), dentist and dental assistant, in addition to community health agents. The inclusion criteria was to be an ESP team professional working at the moment of the research; and currently being on leave served as exclusion criterion.

In the first phase - Institutional and methodological preparation, three meetings were held between the researcher, representatives of the Municipal Health Department, Coordinators of Family Health Strategies and the Management Collegiate, in an effort to discuss the research proposal and plan for data production. Eight meetings were determined for research activities, including location, date, time and the preparation of an Introductory Seminar, which would serve as the first meeting with the participants invited to take part in the study. These meetings occurred between March and August 2012, during which time the project was finalized and submitted to the UNIFESP Ethics Committee and approved.

The second phase - Preliminary and provisory study of the zone and population to be studied, began in September 2012, with the Introductory Seminary attended by the research team and participants. At this moment, researchers formally presented the project to those attending, while also handing out the Informed Consents for signature. After collecting the informed consents, researchers handed out questionnaires assessing the participant's sociodemographic data. Once the questionnaires were collected, researchers organized participants into five subgroups to dis- cuss the inductive questions: "What is violence to you?" and "How is care provided to women in situations of violence in your reality?" and prepare posters to present their ideas to the group as a whole. A total of $41 \mathrm{ESF}$ professionals participated in this meeting.

The phase: Critical analysis of problems considered priority and that researchers hope to study consisted of two working meetings, one in September and one in October. A total of 31 professionals participated in the first meeting in an effort to identify situations that limit and enable care to women in situations of violence. The second meeting was attended by 33 ESF professionals aiming to expand on discussions regarding limits and possibilities and to determine causes, solutions and actions to improve care practices. Both meetings were conducted with the presentation of posters containing summaries of discussions in a large group.

The phase: Programming and execution of an action plan was comprised of two meetings, three pedagogical workshops and a final seminar, held in October, November and December 2012, respectively. Meetings served as continuation of discussions of problems (limitations on practices), causes, solutions and actions to define practical problems and organize the planning of the pedagogic action by choosing themes, content, references and methodology for workshops. A total of 34 participants attended the third meeting, while a researcher and a group representative attended the fourth meeting.

Workshops were held during November and December, covering the following themes: violence against women, beyond the biological dimension, approaching and receiving women in a situation of violence and integrated healthcare network for women in a situation of violence, and were attended by 34, 18 and 33 ESF professionals, respectively. The Final Seminar sought to evaluate the learning/transformations perceived by professionals, possibilities and difficulties in continuing these actions, and was attended by 28 ESF professionals.

The dynamics of meetings, workshops and seminars were focused on dialogue and debate in small groups, followed by an oral presentation to a large group that may include posters. These encounters were based on theoretical references from articles and official documents on policies to curb violence against women in the discussion of cases, in addition to dramatizations and video presentations. Any empirical material produced was recorded and transcribed, for later analysis of 
thematic content in accordance with the Bardin ${ }^{13}$ method.

This study discussed the Integrated Healthcare Network, from which the following subcategories emerged: Untied Healthcare Network lacking protocols, Fragmentation of network services and inefficiency among police, justice and security sectors.

To ensure anonymity, participants were identified by with the letter P, for "participant," followed by a number representing the order in which they spoke, to represent an individual's idea, and RG for "group rapporteur", following the order of presentation, to represent a group's idea.

\section{Results and discussion}

With regards to the subcategory Untied healthcare network lacking protocols, the professionals interviewed in this study pointed out that in their city, services that make up the integrated healthcare network for women in a situation of violence did not work using protocols and workflows. They were untied, with no connection, something that was only confirmed by speakers' words:

The lack of a protocol, of a flow chart or a local service protocol [...] and following the flow. P8

That is what is missing: them [other sectors] working with us [ESP] [...] there are no network services. GR13

When you are dealing with a pregnant women, you know what to do with her, that where she goes she will receive information and counter-information [...], but when you are dealing with violence, you don't know where to send her, there is no one to take her in, services are not continued, she's simply going to bounce from one place to another [...] she'll go to a group so it doesn't happen again. GR5

Family healthcare professionals must work as a team, exchanging information between colleagues and the women living in situations of violence, to improve the implementation of care projects created by a team and shared among all involved. The ESF teams are unable to meet all different types of demands and must seek support from other sectors that make up the intersectoral network. In this sense, knowledge of complementary services available in the community, city and region and how they function provides the professional with a vision of what is provided to women in situation of violence in terms of support, through the implementation of public policies and the recognition of the problem as transversal and collective ${ }^{7}$.
A study in the city of Porto Alegre/RS, showed that many services lacked service protocols, records of cases taken in for notification and an evaluation of care provided. Professionals in the sector also offered a wide range of opinions as to the concepts that serve as a basis for the practice, and often actions are guided by moral values or biological understanding ${ }^{14}$.

The absence of an articulated network that serves as a benchmark for cases of violence against women was observed in a study conducted among professionals at a primary care unit in the city of Sao Paulo/SP, where the referral of women to other services was the fruit of personal initiatives $^{15}$.

When care practices are founded in personal attitudes, no connection is made between institutions, nor is there a flow between services ${ }^{16}$. Reference and counter-reference methods must be established by all members of the network to ensure improved relations between professionals in the construction of these flows ${ }^{7}$. Nonetheless, a study conducted in a city in the metropolitan area of Sao Paulo revealed that there is very little space for exchanges among professionals from institutions that make up the network, leading to untied practices in which discussion and planning of how to help women based on their condition is nearly inexistant ${ }^{16}$.

The practices and postures found among professionals from several different sectors are quite distinct and broken, and this fragmented configuration of the network can make women's search for institutional support ${ }^{16}$ even more difficult, leading them to face the situation on their own ${ }^{17}$.

The incomplete nature of services and individual character of practices that make up the support network for women in a situation of violence has little chance of making these services efficient ${ }^{16}$.

While recognizing that each woman will follow their own path out of a situation of violence, even from within the network, creating protocol and a defined flow provides professionals with safer conditions for their jobs, making the services interorganizational ${ }^{16}$.

The need for protocols within the service network may help to organize intersectoral actions, however it is important to ponder their use, given that the complexity of the problem requires many different solutions, meaning that technical care projects based on single, fixed protocols may not guarantee the most efficient results. Constant contact between organizations that make up the healthcare network, via forums and meetings 
marked by discussions to evaluate how work is organized, may work to maintain the support that each sector needs to focus practices on women's rights ${ }^{6}$.

As such, the flexible character of the network implies in a constant revision of services, how they function and the flow chart established for women's services, given the particular nature of cases. This means that there is no set order for intake or referrals, no exclusive management nor one single intake or strict flow of patients ${ }^{6}$.

As for care practices provided by professionals on family healthcare teams, it is clear that professionals were not prepared to work with violence against women within a network, due to lack of training, as shown by the following transcriptions:

The lack of a team qualified to deal with situations of violence [against women]. P12

Professionals are unprepared to work within a network. P9

The lack of training among healthcare professionals regarding work within a network was discovered by a study conducted in Ribeirao Preto/SP, and can be solved by training professionals to take in women in a situation of violence ${ }^{18}$. A similar situation was identified by a study in the city of Porto Alegre/RS, in which healthcare professionals were aware of policies to fight violence against women, however stated that services were not operating in accordance with recommendations and, as such, felt unprepared to meet these demands ${ }^{17}$. In order to train healthcare professionals in identifying women's' needs within the context of gender violence, it is absolutely essential to support them in overcoming the weaknesses of assistance practices ${ }^{15}$.

Surely, in order to work within a network, professionals must be trained during their specializations, later participating in continued training through courses, seminars, conferences and other forms, as well as continuing their own education, backed by themes that support operations within a network ${ }^{6}$.

In the subcategory Fragmentation of network services, professionals covered by the study expressed the lack of a system for reference and counter-reference as limiting their practices, confirmed by interviews:

So you send a person to a service to get her help, and you never hear anything back, you wait and have no idea what happened to her, and you only see her again when she comes back for more help, after being beaten again, and you start everything over again. $\mathrm{P6}$
If you don't call and follow up, they don't give us any news - it seems like healthcare services compete with care and social services. I think the problem lies with municipal administration, it always has - each department works alone, each helps its own patients, and no one has figured out that they are the same patients. The people that I see are the same ones seen by CREAS, the same ones that go to CRAS, from Palmeira. I think we will be serving our patients if we refer them with this in mind, that we have to refer them, and they know that have to take the patient in and later refer them back to us. P9

One problem that does not come solely from violence, when taking about reference and counter-reference, is following-up on the patient over time. Many times, you see the patient, give her a referral and think you have solved the patient's problems. She goes home and you never hear anything else. She falls back into a repeated situation or the situation changes very little, because she will continue to be a victim of violence because nothing has changed. GR2

When services are provided in an untied manner, lacking in partnerships, care becomes fragmented and follows the bias of each professional. A study conducted in Ribeirao Preto/ SP, Brazil proved that a lack of understanding of network services and their skills and actions led to loose, fragmented care without an established flow, making it nearly impossible to monitor women in situations of violence ${ }^{18}$. In this case, a network cannot simply be comprised of reference points with practices that are limited to triage or referral locations, without a clear understanding of the services provided by other sectors, such as time, location and intake conditions ${ }^{7}$.

Even the existence of a set of distinct services that take in women in a situation of violence, acting in accordance with each sector's specific skills but without a clear understanding of the other existing services is unable to guarantee actions that drive a woman to leave a situation of violence. A dialogue must be created between institutions that make up the network, with greater power of communication between professionals, in order to create shared assistance projects ${ }^{6}$.

In this area, a study conducted in three Brazilian capital cities revealed relations between the police and justice sectors and between the healthcare and social assistance sectors, while highlighting a complete lack of ties between the two subgroups or other sectors ${ }^{6}$. There is evidence that primary care professionals feel a need for improved communication with the police, given that women often access this service, both 
are part of the network and once the latter has been involved, the problem becomes a legal issue. Improving communication and cooperation between different services is the basis for overcoming obstacles that stand in the way of creating an effective network ${ }^{19}$.

The need to improve dialogue is the direct result of actions conducted by anti-violence services with intervention goals that are limited to their sector. Actions that improve connections, the knowledge of service goals and institutional cultures will aid in overcoming this obstacle ${ }^{6}$.

The complete absence of a reference and counter-reference organization within the service network can lead to women being referred to other sectors without follow-up or a concern with solving the issue at hand ${ }^{7}$. Even so, the system can be structured based on the creation of a qualified team, knowledge of network referrals and the collaboration of different sectors and the social structures in place to aid women in a situation of violence ${ }^{18}$.

Creating network care practices is still a challenge for PC focused on ESP and, as such, one sees very little impact from intersectoral actions. The intersectoral policy is essential to facing situations with social causes, and the healthcare sector must work together with other sectors that possess the specific knowledge needed to improve the quality of life of users. Therefore, this system requires greater incentives from local policies ${ }^{20}$.

The subcategory Inefficiency of police, justice and security sectors is understood by professionals as an obstacle to reporting violence against women, and many women opt to not report this type of violence due to their lack of faith in the legal system, shown by the following transcriptions:

Reports are not always resolved and it is for this reason that many people fail to report these cases to the police. Why press charges if nothing is going to be done about it? This is one of the cases in which evidence does not help. She has to go for a restraining order just to get him out of the house. She has to wait for the police to come and remove him. This is not a quick process, and he could simply kill her in the mean time. GR5

The feeling of impunity, of reporting her partner repeatedly and not getting a response from the justice system. GR3

Reports, when made to Women's Police Stations, are sent to a judge who grants a restraining order within 48 hours. However, this process does not always work. Aggressors are not charged and punished, while the police, when requested, are not quick to respond or provide protection, and when quick to respond, are often incapable of providing the aid required ${ }^{14}$.

The lack of value police give to services to women in a situation of violence is proof of their disregard for this issue, leading women lose faith in this sector. Many women seek out the police to punish their aggressor, only to face actions that only serve to reinforce the idea that violence is the result of conflicts and the aggressor is an uncontrolled person, with social and physical power, while the victim is a passive being with less physical and social power in the relationship, leading to a situation that results in violence ${ }^{5}$.

The lack of preparation among professionals that work in police stations, including those specializing in protecting women, with regards to demands that go beyond merely reporting a crime, with difficulty in advising women of their rights, considering that, in most cases, it is the police station that women first seek out when faced with this type of situation ${ }^{6}$.

Judges issue restraining orders based on articles 25 and 26 of the Maria da Penha Law and have little concern regarding how the issue will be resolved. This problem is only aggravated by the belief among many that criminal proceedings do not exist to solve family issues. This concept of the practice is permeated by common sense, suffering from a gender bias, limiting actions to promote protection of women and the punishment and education of the agressor ${ }^{19}$.

In addition to limits on actions, women face a number of institutional obstacles, such as: the impossibility of inspecting compliance with legal orders, lack of appeals and social equipment, such as group homes that operate from 8 am to 6 pm, Monday through Friday, and a specific forum for violence against women. The excess number of criminal proceedings that public prosecutors face leads to delays in the execution of punitive measures. As such, the Maria da Penha Law made great strides in actions to limit violence, but requires greater support from public administrations to ensure the installation of equipment that is lacking to create a true support network ${ }^{19}$.

Within the scenario of the present state of affairs, there is a Police Station with a Women's Registry Office that serves women in a situation of violence and is run by a female clerk that listens to the women and records the facts of the occurrence. From this point, similar to the studies mentioned, the women begin to face a lack of support from other sectors, either because they are unable to include her in the network or because the network does not exist. 
Discrimination by professionals at the police station is one aspect highlighted by professionals as conduct that leads many women to believe that this service is unable to help them, as confirmed during meetings:

In truth, there is discrimination among those that work at the police station, they discriminate, because they see a women walk in to the police station bleeding, and without even knowing it, they look at here in a different light. And we all known that women who have been victimized by their partners come to the police station, and they suffer discrimination, including from the male professionals that work there. RG2

Within the network there are a number of different actions to approach the issue, some of which are based on understanding that considers the woman's intersubjectivity, promoting greater empowerment, while others are more objective, and therefore place blame, in which humiliation and other types of violence suffered by women are accepted and justified by the woman's inadequate behavior and expressed by professionals within the Women's Police Station ${ }^{17}$.

This stereotype seen among male professionals working at Police Stations was observed in a study conducted in a region of the city of Sao Paulo, in which their behavior only served to reinforce the idea that the women is guilty for the conditions in which she lives, thereby removing all value and dismissing her suffering. In this sense, the creation of a Women's Police Station is an alternative that uses the Maria da Penha Law as the basis for actions and referring women to other services, however in reality, this area is full of obstacles, including the lack of training among professionals when faced with more serious cases, leading to an excessive number of referrals to group homes and reference centers, which end up overcrowded and lacking space for other women $^{21}$.

As for restraining orders, when issued, professionals state that couples living in their area of jurisdiction and living in a situation of violence with a restraining order did not respect the legal order. As a result of fear of the husband's threats and insecurity as to a police response, the victim would allow her partner to remain in the home. The partner, for his part, would not leave the home due to a lack of police oversight, delays in training and the non-existence of more severe measures. Other issues include untreated chemical or alcohol dependence, which often leads to extreme violence against women, as proven in meetings:
We saw a case in our area, there is a woman with a restraining order, but she is afraid of her husband and lets him stay at home, and she says that she is afraid that he will burn down the house when the kids are asleep. P15

There [...] simply is no continuation, no punishment for the aggressor. We have the Maria da Penha Law, but there doesn't seem to be any continuity, they just go and issue a restraining order and the parties do not respect it. $\mathrm{P} 6$

This only gets worse if the aggressor is an alcoholic. If he is violent, the restraining order only serves to up the pressure, so no, when he is intoxicated, he's not going to think about the restraining order, it may just make things worse, making him more aggressive. Many women are afraid of restraining orders for this very reason. P9

Studies reveal that women in a situation of violence do not believe in the Maria da Penha Law as providing effective support, due to non-compliance with restraining orders by aggressor ${ }^{17}$, which was also perceived among professionals in this scenario.

Among certain parts of society, particularly the legal system, there is a refusal to use the Maria da Penha Law, based on criticism regarding the dangerous nature of restraining orders as a catalyst for violent actions by the agressor ${ }^{17}$, only serving to bolster the results of this study.

Chemical dependence among partners is also highlighted as a factor that leads to violence and recurrence, a conditional of social vulnerability that limits the law's actions ${ }^{22}$ and, in may cases, the legal system sends aggressor for psycho-social or healthcare services for treatment, without providing the women with the necessary protection, only serving to reinforce their lack of faith in the service $^{17}$.

Since the approval of the Maria da Penha Law, there has been a continual increase in the number of reports, particularly those to Women's Police Stations $^{17,22}$. In addition to the increase in reported cases, we have also noted a decrease in the severity of the occurance ${ }^{14}$. Nonetheless, cases in which the aggressor was sentenced are still rare ${ }^{17}$.

In fact, the Maria da Penha Law has led to positive changes in the lives of women living in situations of violence, giving them the chance to report violence to a special police department and begin legal proceedings to punish their aggressor, thereby exercising their right to protect their lives. Another aspect is that the law led to a reorganization of healthcare and security services, which began to recognize violence as an issue that requires a specific, organized approach ${ }^{22}$. 
We have seen proof of defenders of the Maria da Penha Law, which is not to say that they execute the law in practice or maintain efficient communication between sectors that make up the network in an effort to ensure inter-institutional interactions to protect women. This is still quite a challenge, as many locations and regions still lack Special Women's Police Stations, sufficient number of well-trained professionals or Domestic Violence Courts to address the issue in accordance with the law. Furthermore, judges must be informed of cases on non-compliance by aggressor so that they might take the steps necessary, involving public security forces, to ensure that the woman feels safe with regards to the restraining $\operatorname{order}^{14}$. One of the sectors that is most separated from other services is the legal system, which contributes significantly to difficulties in establishing a network approach ${ }^{6}$.

\section{Conclusion}

Services that make up the healthcare network for women in a situation of violence do not work with protocols or flows, are untied, fragmented and lack an organized system for reference and counter-reference.

The inefficiency of the police, justice system and security forces are understood by professionals as factors that serves as obstacles to women reporting violence, resulting from a lack of faith among victims in the legal system.

Discriminating conduct among police professionals at police stations is highlighted as a practice that drives women away instead of listening to the subjective issues and demands that make up the social field.

Couples that live in areas of jurisdiction and live in a situation of violence under a restraining order do not respect legal rulings. The victim lives in fear of her husband's threats and the unreliability of effective police actions. The aggressor often disregards legal rulings due to a lack of police response and delays in trials, in addition to a lack of more severe measures or untreated chemical or alcohol dependence, making the aggressor incapable of judging their own actions and may lead to extreme cases of violence against the women in question. Working to solve these issues is quite a challenge for professionals, giv- en that many operate under the conception that the women should follow the route away from violence that beings with a report, request for restraining order, divorce, punishment of the aggressor and beginning of a new life, as if it were some sort of script to be followed by all women. The inability to follow this script due to challenges along the way that depend on others often leaves them frustrated.

The lack of preparation to work with violence against women and within a network, due to lack of training, and the extensive nature of the ineptitude seen at police stations, the practices of which are focused on the reporting of crime within strict protocols, treating anything that is not routine with little attention, value and acceptance that the problem is private, play significant roles in maintaining violence invisible.

The limits on network care are present in this context and are cited as situations that limit the practices of ESF professionals, which live with demands they are incapable of meeting and, as such, return the women to a situation of re-victimization.

Questioning these limits allows for a clear perspective of the need for improvement in dialogue between sectors and the creation of a space for discussion to prepare protocols and flows that guide collective care practices that can actually protect the life and health of women that live in a situation of violence.

This study reiterates the understanding that the intersectoral network of services for women in a situation of violence must be created and strengthened, to allow for access from any point and ensure that it is followed with the participation of all involved in an articulated fashion, with dialogue and institutional commitment.

As such, the support and incentives of managers of local sectors and national, state and regional policies that guide and finance policies for reducing violence against women must be available and accessed. Partnerships with universities and government and non-government organization in projects that support the creation of network care practices may serve to reorganize practices based on a collective model, thereby consolidating more efficient services while contributing to the education and training of professionals within the network. 


\section{Collaborations}

EB Silva participated in the creation, delineation, analysis and interpretation of data and preparation of the article. SMP Mello participated in the delineation, analysis of data and critical revision of the text. LAC Vianna participated in the critical analysis and final creation of the text.

\section{References}

1. World Health Organization (WHO). Global and regional estimates of violence against women: prevalence and health effects of intimate partner violence and nonpartner sexual violence. Geneva: WHO; 2013.

2. Joner K, Mash B. A comprehensive model for intimate partner violence in primary care South Africa: action research. BMC Health Serv Res 2012; 12:399.

3. Joner K, Mash B. The value of intervening for intimate partner violence in primary care African South: project evaluation. BMJ Open 2011; 1(2):e000254.

4. Silva RA, Araújo TVB, Valonguerio S, Ludermir AB. Enfrentamento da violência infligida pelo parceiro íntimo por mulheres em área urbana da região Nordeste do Brasil. Rev Saude Publica 2012; 46(6):1014-1022.

5. Santi LN, Nakano AMS, Lettiere A. Percepção de Mulheres em situação de violência sobre o suporte e apoio recebido em seus contexto social. Rev Texto e Contexto de Enfem 2010; 19(3):417-424.

6. Shraiber LB, D’Oliveira AFPL, Hanada H, Kiss L. Assistência a mulheres em situação de violência - da trama de serviços a rede intersetorial. Rev Athenea Digital 2012; 12(3):237-254.

7. D'Oliveira AFPL, Scharaiber LB, Hanada H, Durand J. Atenção integral à saúde de mulheres em situação de violência de gênero- uma alternativa para a atenção primária em saúde. Cien Saude Colet 2009; 14(4):10371050.

8. Brasil. Secretaria de Políticas para as Mulheres. Pacto Nacional de Enfrentamento à Violência Contra as Mulheres. Brasília: Secretaria de Políticas para as Mulheres; 2010.

9. Oliveira CC, Fonseca RMGS. Práticas dos profissionais das equipes de saúde da família voltadas para as mulheres em situação de violência sexual. Rev Esc Enferm USP 2007; 41(4):605-612.

10. Osis MJD, Duarte GA, Faúndes A. Violência entre usuárias de unidades de saúde: prevalência, perspectiva e conduta de gestores e profissionais. Rev Saude Publica 2012; 46(2):351-358.

11. Haguette MTF. Metodologias qualitativas na sociologia. $13^{\mathrm{a}}$ ed. Petrópolis: Vozes; 2011.

12. Le Boterf G. Pesquisa participante: propostas e reflexões metodológicas. In: Brandão CR, organizador. Repensando a Pesquisa Participante. São Paulo: Brasiliense; 1985. p. 51-81.

13. Bardin L. Análise de Conteúdo. Lisboa: Edições 70; 2011.

14. Meneguel SN, Mueller B, Collaziol ME Quadros MM. Repercussões da Lei Maria da Penha no enfrentamento da violência de gênero. Cien Saude Colet 2013; 18(3):691-700.

15. Guedes RN, Fonseca RMGS, Egry EY. Limites e possibilidades avaliativas da Estratégia de Saúde da Família paraviolência de gênero. Rev Esc Enferm USP 2013; 47(2):304-311.

16. Dutra ML, Prates PL, Nakamura E, Villela WV. A configuração da rede social de mulheres em situação de violência doméstica. Cien Saude Colet 2013; 18(5)12931304. 
17. Meneguel SN, Bairros F, Mueller B, Monteiro D, Oliveira LP, Collaziol ME. Rotas críticas de mulheres em situação de violência:depoimento de mulheres e operadores em Porto Alegre, Rio Grande do Sul, Brasil. Cad Saude Publica 2011; 23(4):743-752.

18. Santos MA, Vieira EM. Recursos Sociais para apoio as mulheres em situação de violência em Ribeirão Preto, SP, na perspectiva de informantes chave. Interface (Botucatu) 2011; 15(36):93-108

19. Vieira EM, Ford NJ, De Ferranti FG, Almeida, AM, Daltoso, D. Santos MA. A resposta a violência de gênero entre os profissionais brasileiros. Cien Saude Colet 2013; 18(3):681-690.

20. LA, Casotti CA, Chaves SCL. A produção científica brasileira sobre a Estratégia Saúde da Família e a mudança no modelo de atenção. Cien Saude Colet2013; 18(1):221-232.

21. Villela WV, Vianna LAC, Lima LFP, Sala DCP, Vieira TF, Vieira ML, Oliveira EM. Ambiguidades e Contradições no Atendimento de Mulheres que sofrem violência. Rev. Saúde e Soc 2011; 20(1):113-123.

22. Alves ES. Oliveira DLLC, Maffacioli R. Repercussões da Lei Maria da Penha no enfrentamento a violência doméstica em Porto Alegre. Rev Gaúcha de Enferm 2012; 33(3):141-147.

Artigo apresentado em 29/08/2013

Aprovado em 20/10/2013

Versão final apresentada em 29/10/2013 